\title{
Skin Thickness in Children Treated With Daily or Periodical Inhaled Budesonide for Mild Persistent Asthma. The Helsinki Early Intervention Childhood Asthma Study
}

\author{
MARKKU TURPEINEN, HANNA RAITIO, ANNA S. PELKONEN, KURT NIKANDER, RITVA SORVA, OLOF SELROOS, \\ KAISU JUNTUNEN-BACKMAN, AND TARI HAAHTELA
}

\author{
Department of Allergy [M.T., H.R., A.S.P., R.S., K.J.-B., T.H.], Helsinki University Central Hospital, FIN-00250 Helsinki, Finland; \\ AstraZeneca R\&D [K.N.], SE-221 85 Lund, Sweden; Semeco AB [O.S.], SE-260 83 Vejbystrand, Sweden
}

\begin{abstract}
In adults, asthma treatment with high doses of inhaled corticosteroids has resulted in dermal thinning. The aim of this study was to investigate the skin thickness in children with asthma during budesonide treatment. In a double-blind study, 113 children, 5-10 y old, with persistent asthma received budesonide $400 \mu \mathrm{g}$ twice daily for $1 \mathrm{mo}$ and thereafter $200 \mu \mathrm{g}$ twice daily for $5 \mathrm{mo}$. Thereafter, 56 children received $100 \mu \mathrm{g}$ twice daily for $1 \mathrm{y}$, whereas 57 other children used budesonide periodically for exacerbations. An additional 54 children were treated with disodium cromoglycate (DSCG) for $18 \mathrm{mo}$. Skin thickness was measured on each forearm before and after treatment for 6,12 , and 18 mo using a $20-\mathrm{MHz}$ high-resolution ultrasonic device. The initial 6-mo budesonide treatment resulted in a greater reduction in mean skin thickness in the forearms compared with DSCG (right: -35.9 versus $-5.9 \mu \mathrm{m} ; p=0.004$; left: -30.6 versus $-7.3 \mu \mathrm{m} ; p=0.03$ ). At month 18 , the inter-group differences were no longer significant. Budesonide inhalations in daily doses of $400-800 \mu \mathrm{g}$ in prepubertal children with newly detected asthma may cause minor dermal thinning. The changes were reversible during low dose or periodic treatment with budesonide. (Pediatr Res 67: 221-225, 2010)
\end{abstract}

$\mathrm{I}^{\mathrm{n}}$ nhaled corticosteroids (ICS) are recommended first-line treatment for all patients with persistent asthma (www.ginasthma. com, 1). However, ICS may have systemic effects. High doses of ICS may result in purpura and dermal thinning $(2,3)$. In older subjects, e.g. postmenopausal women, a correlation between bruises and the duration of treatment and accumulated ICS dose has been proposed $(3,4)$. Studies on concentrations of procollagen propeptides in suction blister fluid reflecting skin collagen synthesis in vivo suggest that collagen production in the skin is reduced even during low dose treatment with ICS (5). In a longitudinal study, ICS decreased the collagen synthesis of skin in adults, but skin thickness was not markedly changed after 1-2 $\mathrm{y}$ of treatment (6).

The aim of this study was to assess, objectively and prospectively, the skin thickness in children with newly diagnosed mild persistent asthma during 18 mo regular or periodic treatment with budesonide, a well-documented ICS. The find-

Received April 29, 2009; accepted October 3, 2009.

Correspondence: Markku Turpeinen, M.D., Ph.D., Department of Allergy, Skin and Allergy Hospital, Helsinki University Hospital, Meilahdentie 2, FIN-00250 Helsinki, Finland; e-mail: markku.t.turpeinen@hus.fi

Supported by the Helsinki University Central Hospital (grant TYH 2303) and AstraZeneca, Lund, Sweden. ings were compared with those in asthmatic children treated with inhaled disodium cromoglycate (DSCG). DSCG has an excellent safety record (7) and no reports on skin atrophy have been published. However, its antiasthmatic effect is considerably milder than that of ICS (7).

\section{METHODS}

Subjects and design. Children aged 5-10 y with newly detected asthma participated in a partially double-blind, randomized, parallel-group, and single-center 18-mo study (8). Children with chronic diseases other than asthma that could influence the performance of the study or interpretation of study results were excluded, as were children with atopic dermatitis of moderate or severe grade (extent of dermatitis $>15 \%$ of body surface area). Children with a history of inhaled, nasal or oral corticosteroid use during the last 2 mo before the study were also excluded, as were children who had used topical steroids more potent than hydrocortisone for treatment of skin areas $>1 \%$ of the total body surface area and in an amount of $>30 \mathrm{~g}$. Children with sexual development of Tanner stage $>2$ were excluded from the analysis of skin thickness.

Treatment. All children had mild persistent asthma and were randomized in balanced blocks into three treatment groups: 1) continuous budesonide (400 $\mu \mathrm{g}$ twice daily for $1 \mathrm{mo}, 200 \mu \mathrm{g}$ twice daily for months $2-6,100 \mu \mathrm{g}$ twice daily for months $7-18$ ); 2) budesonide/placebo (identical treatment as in group 1 during months $1-6$, but thereafter placebo for months 7-18); and 3) DSCG $10 \mathrm{mg}$ three-times daily for months 1-18 administered open label. This dosing of DSCG was based on the Pediatric Consensus Statement (9). Exacerbations in all three groups were treated with budesonide $400 \mu \mathrm{g}$ twice daily for a 2-wk period (8). This means that children in the budesonide/ placebo group received periodic treatment with budesonide during months 7-18. Children with frequent exacerbations (frequent defined as a time interval of $\leq 2$ mo between two exacerbations) received in addition oral theophylline (Theo-Dur, AstraZeneca, Södertälje, Sweden) for $6 \mathrm{wk}$ in a daily dose of $10-15 \mathrm{mg} / \mathrm{kg}$ body weight. Children requiring treatment with oral prednisolone for an exacerbation were excluded.

Outcomes. The study had 15 clinic visits: a screening visit, a baseline visit, and visits after treatment for 1,2 , and 3 mo and there after every $6 \mathrm{wk}$. The main outcome variables were the changes in morning peak expiratory flow rates, number of asthma exacerbations, and growth. The results of these variables have been previously reported (8). At baseline (visit 2) and after treatment for 6 (visit 7), 12 (visit 11), and 18 mo (visit 15), the patients were seen by the dermatologist (H.R.), who performed skin measurements and was blinded to the treatments.

The measurement of skin thickness was performed with a 20-MHz highresolution ultrasonic device (DUB 20, Taberna Pro Medicum, Luneburg, Germany) (10). This method has previously been used in similar type studies (11-13). For obtaining skin data on the forearm, the distance between epicondylos medialis humerii and processus styleoideus radii was measured. The midpoint of the distance on the medial side of the forearm was chosen for the measurements of skin thickness. Three measurements in this defined area on each forearm were performed, and the median values were used for analysis. Measurements were not made on any eczematous areas of the skin.

Abbreviations: DSCG, disodium cromoglycate; ICS, inhaled corticosteroid 
Table 1. Baseline characteristics of the patients (all patients with baseline measurements of skin thickness)

\begin{tabular}{lccc}
\hline \multicolumn{1}{c}{ Treatment group } & Continuous budesonide & Budesonide/placebo (periodic budesonide) & Disodium cromoglicate \\
\hline No. of patients & 56 & 57 & 54 \\
Age $(\mathrm{y})$ & $6.9(5-10)$ & $6.6(5-9)$ & $6.8(5-10)$ \\
Male $(\%)$ & 61 & 67 & 56 \\
Skin prick test positive $(n)$ & 33 & 24 & 31 \\
Rhinitis & 12 & 14 & 12 \\
Atopic dermatitis & 12 & $94(69-116)$ & 8 \\
FEV $(\%$ predicted value) & $92(61-114)$ & $909(705-1095)$ & $94(66-125)$ \\
Skin thickness, right forearm $(\mu \mathrm{m})$ & $931(737-1163)$ & $912(742-1106)$ & $910(790-1111)$ \\
Skin thickness, left forearm $(\mu \mathrm{m})$ & $923(695-1169)$ & & $915(790-1121)$ \\
\hline
\end{tabular}

Values are means with ranges in parentheses, unless otherwise stated.

$\mathrm{FEV}_{1}$, forced expiratory volume in 1 second. Predicted normal $\mathrm{FEV}_{1}$ values were calculated according to Ref. 14.

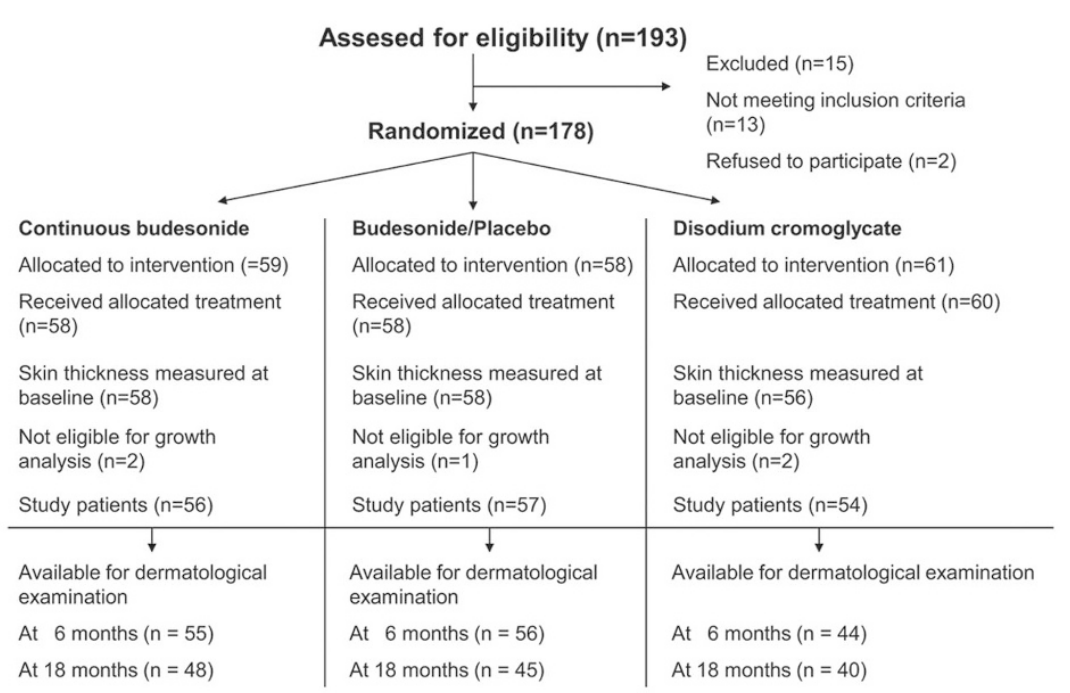

Figure 1. Flow chart of the patients.

A group of healthy children was examined with the same equipment as the asthmatic children to obtain normal values. The accurate function of the device was validated daily on the same skin area of the examiner before measurements were performed in study patients. Calibration was performed without water on the skin (zero calibration).

The study was performed in accordance with the Declaration of Helsinki and Good Clinical Practice and was approved by the Ethics Committee of the Helsinki University Central Hospital. Written informed consent was obtained from each patient's parent(s) or legal guardian and from the patient.

Statistical analysis. The sample size for the main study was determined by power calculation for morning peak expiratory flow rates (8). Skin thickness data were analyzed using the intention-to-treat principle; that is, all patients who had taken at least one dose of study medication and who had data for the required period(s) were included in the analyses. Withdrawn patients were handled using the "last value extended" principle within period. Comparisons for months 1-6 were made between the combined budesonide groups and the DSCG group as both budesonide groups had had identical treatments; comparisons at 12 and 18 mo were made between all three groups.

The changes in skin thickness were analyzed using an ANOVA model with fixed factor treatment and baseline values as a covariate.

\section{RESULTS}

Patient demographics. The baseline characteristics of the study population are shown in Table 1 . A total of 167 children had baseline measurements of skin thickness. No important changes were seen in baseline characteristics when only those children remaining in the study after treatment for 6,12 , and 18 mo, respectively, were considered. The majority of the children were atopic based on skin prick tests to at least one common allergen. A few also had rhinitis or atopic dermatitis. None of the children with atopic eczema developed any worsening of their skin disease that could not be treated with hydrocortisone cream $(1 \%)$. No one was withdrawn because of dermatitis.

Our aim was to study the effects of ICS on prepubertal children. At 18 mo, two children in the continuous budesonide group and one child both in the budesonide/placebo and DSCG group presented with Tanner stage $>2$. They were excluded from the analysis of skin thickness.

Performance of the study. Figure 1 shows the flow of the patients through the study. Of the total of 178 randomized children in the main study 172 had skin thickness measurements at baseline. A total of 167 were available for analysis of skin thickness when the five patients with Tanner stage $>2$ had been excluded. A total of 12 children discontinued the study before the 6-mo evaluation and a further 22 children before the 18 -mo evaluation. Table 2 shows the mean doses of budesonide used in the three treatment groups.

Skin thickness. The mean skin thickness and ranges in the three study groups at baseline are shown in Table 3. There were no statistically significant differences in skin thickness between the study groups. In 19 healthy children, the median skin thickness in the right forearm varied between 758 and $1058 \mu \mathrm{m}$ and in the left forearm between 758 and $1027 \mu \mathrm{m}$ with a within-subject coefficient of variation for the three measurements of $3.3 \%$.

The changes from baseline in skin thickness are presented in Figure 2. The median skin thickness (in $\mu \mathrm{m}$ ) at baseline and 
Table 2. Median daily doses of budesonide, $\mu \mathrm{g} /$ day (range) during the study

\begin{tabular}{cccc}
\hline Period & Continuous budesonide $(n=56)$ & Budesonide/placebo $(n=57)$ & Disodium cromoglycate $(n=54)$ \\
\hline 0- to 6-mo period & $471.6(454.2-800.0)$ & $467.0(456.8-540.4)$ & $64.3(0.0-417.6)$ \\
7- to 18-mo period & $224.2(200.0-423.8)$ & $32.6(0.0-487.0)$ & $62.6(0.0-288.9)$ \\
0- to 18-mo period & $310.1(275.9-510.5)$ & $193.1(137.8-495.2)$ & $67.4(0.0-236.1)$ \\
\hline
\end{tabular}

In the continuous budesonide group, the children received budesonide twice daily during 18 mo according to the study design. The daily dose was increased if high budesonide doses were used during exacerbation. During placebo and DSCG treatments, the variation of the daily budesonide doses was similarly dependant on the number of exacerbations. Number of patients who received allocated treatment is shown.

Table 3. Skin thickness with group means and ranges at baseline and after 6, 12 and 18 months of treatment and the percent differences and ranges from baseline at the three time points in the study

\begin{tabular}{|c|c|c|c|c|c|c|c|c|c|}
\hline \multirow[b]{2}{*}{ Assessment } & \multicolumn{3}{|c|}{ BUD/BUD } & \multicolumn{3}{|c|}{ BUD/PLA } & \multicolumn{3}{|c|}{ DSCG } \\
\hline & $n$ & Skin thickness $(\mu \mathrm{m})$ & Difference & $n$ & Skin thickness $(\mu \mathrm{m})$ & Difference & $n$ & Skin thickness $(\mu \mathrm{m})$ & Difference \\
\hline \multicolumn{10}{|l|}{ Right forearm } \\
\hline Baseline & 55 & 931 (737 to 1163$)$ & & 57 & 909 (705 to 1095$)$ & & 54 & $910(790$ to 1111$)$ & \\
\hline $6 \mathrm{mo}$ & 54 & 888 (758 to 1053$)$ & $-4.1(-17.0$ to 14.2$)$ & 56 & 874 (700 to 1042$)$ & $-3.5(-24.6$ to 8.5$)$ & 44 & 901 (774 to 1079$)$ & $0.1(-17.2$ to 19.4$)$ \\
\hline $12 \mathrm{mo}$ & 48 & 894 (706 to 1032) & $-2.7(-17.1$ to 15.0$)$ & 47 & 911 (795 to 1021) & $0.7(-12.7$ to 16.4$)$ & 39 & 905 (753 to 1079$)$ & $0.3(-16.9$ to 30.5$)$ \\
\hline $18 \mathrm{mo}$ & 48 & 909 (726 to 1127$)$ & -1.7 ( -18.6 to 16.7$)$ & 45 & $896(774$ to 1000$)$ & $-0.6(-20.5$ to 16.0$)$ & 40 & 911 (774 to 1111$)$ & $0.6(-18.3$ to 20.0$)$ \\
\hline \multicolumn{10}{|l|}{ Left forearm } \\
\hline Baseline & 56 & $923(695$ to 1169$)$ & & 57 & 912 (742 to 1106$)$ & & 54 & 915 (790 to 1121$)$ & \\
\hline $6 \mathrm{mo}$ & 55 & 895 (742 to 1090$)$ & $-2.4(-18.8$ to 14.6$)$ & 56 & 874 (742 to 1042$)$ & $-3.9(-17.2$ to 11.6$)$ & 44 & 901 (742 to 1121$)$ & $0.1(-31.9$ to 17.9$)$ \\
\hline $12 \mathrm{mo}$ & 49 & 887 (758 to 1058$)$ & $-2.4(-15.6$ to 18.7$)$ & 47 & 907 (758 to 1058$)$ & $-0.1(-17.4$ to 20.8$)$ & 39 & 896 (742 to 1106$)$ & $-0.7(-31.9$ to 15.1$)$ \\
\hline $18 \mathrm{mo}$ & 48 & 909 (758 to 1153$)$ & $-1.1(-17.2$ to 16.6$)$ & 45 & 894 (758 to 1058$)$ & -1.1 ( -20.0 to 22.7$)$ & 40 & 907 (758 to 1121$)$ & $0.4(-30.5$ to 18.9$)$ \\
\hline
\end{tabular}

All patients with at least one follow-up measurement were included.

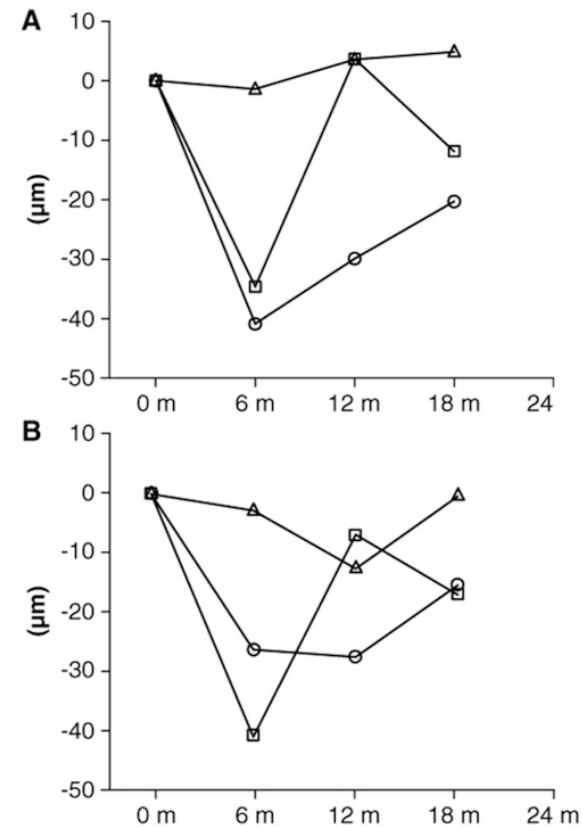

Figure 2. Changes in skin thickness (mean $\pm \mathrm{SD})$ of the $(A)$ right and $(B)$ left forearms after treatment with budesonide for $18 \mathrm{mo}(\mathbf{)})$, budesonide for 6 mo followed by intermittent budesonide ( $\mathbf{\square})$ or DSCG $(\mathbf{\Delta})$. At $6 \mathrm{mo}$, the differences in change in skin thickness between the combined budesonide group and the DSCG group were statistically significant; right forearm $* * p=$ 0.004 ; left forearm $* p=0.03)$. No other significant differences were found.

the percentage change from baseline after 6,12 , and 18 mo treatment are shown in Table 3. After treatment for $6 \mathrm{mo}$, the difference in reduction in skin thickness for budesonide- (combined group) and DSCG-treated children was 23.3 and 30.0 $\mu \mathrm{m}$, respectively (left and right forearm $p=0.03$ and 0.004 , respectively). After treatment for 12 mo, skin thickness in children receiving periodic treatment with budesonide had reached pretreatment values. At $18 \mathrm{mo}$, no statistically signif- icant differences in skin thickness were seen between any of the treatment groups. No statistically significant differences in skin thickness were seen between the right and left forearm at any time points.

\section{DISCUSSION}

ICS, the most effective treatment for asthma (1), have been in clinical use for $>30 \mathrm{y}$. Despite good clinical effects of topical corticosteroids on atopic diseases and extensive safety studies, there is still among patients a certain phobia toward corticosteroids, which may lead to under treatment or early discontinuation of ICS therapy. Different treatment strategies have been suggested and the clinical benefit/risk ratio carefully evaluated. Several reviews have dealt with the risk of ICS-induced side effects, particularly when high doses have been applied $(15,16)$. The long-term effects of ICS on the hypothalamic-pituitary-adrenal axis, statural growth, and bone mineral density have been of special concern (17). Although many aspects of systemic effects of ICS have been thoroughly investigated, and the possible risks are known, there are still areas with limited knowledge, particularly in children. One area where information in the pediatric population appears to be insufficient is the risk of dermal thinning. To our best knowledge, this study is the first one performed in children.

In previous studies in children with asthma (18-20), and in subsequent clinical practice, we have preferred to use a high starting dose that has been tapered to the lowest maintenance dose resulting in good asthma control. We have also applied periodic treatment in children with mild asthma. This doubleblind, randomized, 18-mo study aimed at testing the periodic treatment strategy in a larger number of patients with mild persistent asthma and to compare that strategy with continuous low-dose budesonide and DSCG treatments. The results of the dermatological investigations reported here are a part of 
this clinical study (8). The study seems to show that the initial effect of ICS on skin thickness is dose dependent. Our results are partly in agreement with the results of a longitudinal study in adult Finnish patients (6). In that study, a slight dermal thinning on the forearm was observed after treatment with daily budesonide doses of $800-1600 \mu \mathrm{g}$. The skin thickness was, however, normalized after 1-2 y of continuous therapy suggesting no dose relationship and only a temporary effect on the skin.

Advanced dermal thinning and purpura are well known side-effects of treatment with oral corticosteroids and also with high-dose ICS (2-4). In an observational study in 157 children treated for 3-6y with an average daily dose of $\sim 500$ $\mu \mathrm{g}$ of budesonide, no skin bruising was reported in comparison with 111 control children (22). Skin bruising occurs when the amount of collagen in skin is markedly reduced and this change is irreversible (2) and may be a late side effect associated with the cumulative ICS dose (3). Our study demonstrates that compared with DSCG, moderate-to-high doses of ICS may after 6 mo of treatment cause a slight but statistically significant dermal thinning on the forearms of children. During subsequent treatment with lower doses, the skin thickness returned toward normal. During periodic treatment with budesonide, no significant effect on skin thickness was found. When duration of treatment was analyzed no apparent differences were seen in the correlations between individual doses of budesonide and skin thinning, neither during $0-6,6-12$ nor during $0-18$ mo of treatment. This indicates that within the time frame of this study the effects of ICS on the skin are more likely to be dose dependent than time dependent. However, larger and even longer time studies are needed to confirm this conclusion.

Collagen is the most important structural protein both in the skin and bone. Several studies on procollagen levels in serum and blister fluid of the skin have shown decreased procollagen levels during ICS treatment $(5,6,20,21,23)$. Furthermore, decreased procollagen levels have been shown to be associated with dermal thinning (6). This corroborates our results on dermal thinning during high doses of ICS. A rapid decrease in both bone formation and degradation markers during high-tomoderate dose budesonide treatment in this series of patients could reflect an overall reduction in collagen turnover rate (data not shown). During the low-dose ICS treatment and when ICS was given only as needed, the levels of collagen markers returned to baseline levels indicating that a normal collagen turnover rate was achieved.

In this study, skin thinning occurred during the first 6 mo of treatment. This is the same time frame when a transient decline in height velocity has been observed $(8,24)$. Dermal thinning, like height velocity in our study (8), was dose related, reversible, and normalized during the 12-mo low-dose budesonide treatment or when budesonide was given only as needed (8). Normalization occurred faster when budesonide was given only as needed. For the initial growth retardation a catch-up effect has been described $(8,24)$ and children using budesonide continuously have reached a normal final height (25). It can only be speculated whether the skin thickness of the children in our study would had been normalized also during continuous high-dose treatment.

In this study, high-dose budesonide (400 $\mu \mathrm{g}$ twice daily delivered via Turbuhaler to children with a mean age of $7 \mathrm{y}$ ) resulted in a slight but statistically significant decrease in skin thickness, compared with DSCG, ranging from 31 to $36 \mu \mathrm{m}$ (3.3-3.9\%). Considering the within-subject coefficient of variation in healthy children of $3.3 \%$, we judge the absolute changes in skin thickness induced by ICS as quite modest. The changes were also clearly smaller than those observed in adults inhaling high-dose ICS for several years (15-19\%) (2). However, if the small, statistically significant reduction in skin thickness, observed during high-dose treatment, is cumulative, regular treatment with high daily doses during several years might result in a clinically significant dermal thinning.

The number of asthma exacerbations, influencing overall health status of the children, was lowest in the continuous budesonide group and highest in the DSCG group (8). No correlation was observed between the health state and skin thickness of the children.

Importantly, in our children with mild persistent asthma, low-dose budesonide that did not affect the skin thickness was sufficient to give a good asthma control (8), as was also seen in the large randomized 3-y study (15).

In conclusion, 6 mo treatment with high-dose inhaled budesonide in children with mild persistent asthma resulted in minor dermal thinning that was reversible during low-dose or periodic treatment, which are the preferred regimens for maintenance therapy. The risk of skin atrophy seems to be very low. Monitoring of dermal thickness is not needed in children with mild persistent asthma on ICS therapy.

Acknowledgments. We thank the children and their families for their excellent compliance during this long-term study. We also acknowledge the valuable contribution of Tuula Koljonen, RN, and Leena Ingelin-Kuortti, RN, study nurses, Eeva Kiiskilä and Eva Holtås, study monitors, and Thomas Bengtsson, MSc, Biostatistician.

\section{REFERENCES}

1. Global Initiative for Asthma 2008 Global strategy for asthma management and prevention. Available at: http://www.ginasthma.com. Accessed February 1, 2009

2. Capewell S, Reynolds S, Shuttleworth D, Edwards C, Finlay AY 1990 Purpura and dermal thinning associated with high dose inhaled corticosteroid. BMJ 300:1548-1551

3. Roy A, Leblanc C, Paquette L, Ghezzo H, Côté J, Vartier A, Malo JL 1996 Skin bruising in asthmatic subjects treated with high doses of inhaled steroids: frequency and association with adrenal function. Eur Respir J 9:226-231

4. Mak VH, Melchor R, Spiro SG 1992 Easy bruising as a side effect of inhaled corticosteroids. Eur Respir J 5:1068-1074

5. Autio P, Karjalainen J, Risteli L, Risteli J, Kiistala U, Oikarinen A 1996 Effects of an inhaled steroid (budesonide) on skin collagen synthesis of asthma patients in vivo. Am J Respir Crit Care Med 153:1172-1175

6. Haapasaari K, Rossi O, Risteli J, Oikarinen A 1998 Effects of long-term inhaled corticosteroids on skin collagen synthesis and thickness in asthmatic patients. Eur Respir J 11:139-143

7. König P, Grigg CF 2000 Cromolyn sodium or nedocromil in childhood asthma: does it matter? Clin Exp Allergy 30:164-171

8. Turpeinen M, Nikander K, Pelkonen AS, Syvänen P, Sorva R, Raitio H, Malmberg P, Juntunen-Backman K, Haahtela T 2008 Daily versus as-needed inhaled corticosteroid for mild persistent asthma. The Helsinki Early Intervention Childhood Asthma Study. Arch Dis Child 93:654-659

9. Warner JO, Naspitz CK, Cropp GJ 1998 Third international pediatric consensus statement on the management of childhood asthma. Pediatr Pulmonol 25:1-17 
10. Autio P, Turpeinen M, Risteli J, Kallioinen M, Kiistala U, Oikarinen A 1997 Ehlers-Danlos type IV: non-invasive techniques as diagnostic support. Br J Dermatol 137:653-655

11. Cossmann M, Welzel J 2006 Evaluation of the atrophogenic potential of different glucocorticoids using optical coherence tomography, 20-mhz ultrasound and profilometry; a double-blind, placebo-controlled trial. Br J Dermatol 155:700-706

12. Gomez EC, Berman B, Miller DL 1982 Ultrasonic assessment of cutaneous atrophy caused by intradermal corticosteroids. J Dermatol Surg Oncol 8:1071-1074

13. Josse G, Rouvrais C, Mas A, Haftek M, Delalleau A, Ferraq Y, Ossant F, George J, Lagarde JM, Schmitt AM 2009 A multitechnique evaluation of topical corticosteroid treatment. Skin Res Technol 15:35-39

14. Koillinen H, Wanne O, Niemi V, Laakkonen E 1998 Spirometric and peak expiratory flow reference values of healthy Finnish children. Finnish Med J 53:395-402

15. Pedersen S 2006 Clinical safety of inhaled corticosteroids for asthma in children. An update of long-term trials. Drug Saf 29:599-612

16. Sheffer AL, Silverman M, Woolcock AJ, Diaz PV, Lindberg B, Lindmark B 2005 Long-term safety of once-daily budesonide in patients with early-onset mild persistent asthma: results of the Inhaled Steroid Treatment as Regular Therapy in Early Asthma (START) study. Ann Allergy Asthma Immunol 94:48-54

17. Lipworth BJ 1999 Systemic adverse effects of inhaled corticosteroid therapy. Arch Intern Med 159:941-955
18. Dahl R 2006 Systemic side effects if inhaled corticosteroids in patients with asthma Respir Med 100:1307-1317

19. Turpeinen M, Sorva R, Juntunen-Backman K 1991 Changes in carbohydrate and lipid metabolism in children with asthma inhaling budesonide. J Allergy Clin Immunol 88:384-389

20. Sorva R, Turpeinen M, Juntunen-Backman K, Karvonen S-L, Sorva A 1992 Effect of inhaled budesonide on serum markers of bone metabolism in children with asthma. J Allergy Clin Immunol 90:808-815

21. Sorva R, Tähtelä R, Turpeinen M, Juntunen-Backman K, Haahtela T, Risteli J, Sorva A 1996 Changes in bone markers in children with asthma during inhaled budesonide and nedocromil treatments. Acta Paediatr 85:1176-1180

22. Agertoft L, Larsen FE, Pedersen S 1998 Posterior subcapsular cataracts, bruises and hoarseness in children with asthma receiving long-term treatment with inhaled budesonide. Eur Respir J 12:130-136

23. Birkebaek NH, Esberg G, Andersson K, Wolthers O, Hassager C 1995 Bone and collagen turnover during treatment with inhaled dry powder budesonide and beclomethasone dipropionate. Arch Dis Child 73:524-527

24. Childhood Asthma Management Program (CAMP) Research Group 2000 Long-term effects of budesonide or nedocromil in children with asthma. N Engl J Med 343:1054-1063

25. Agertoft L, Pedersen S 2000 Effect of long-term treatment with inhaled budesonide on adult height in children with asthma. N Engl J Med 343:1064-1069 